\title{
FATORES CRÍTICOS DE SUCESSO À MANUTENÇÃO DE COMUNIDADES DE PRÁTICA: ANÁLISE SOB A ÓTICA DE UM GRUPO DE GESTORES COM CARACTERÍSTICAS PREPONDERANTES AS DE UMA COMUNIDADE
}

\section{Sabrina Rebelo Schmitt}

Mestre pelo Programa de Pós-Graduação em Engenharia e Gestão do Conhecimento da Universidade Federal de Santa Catarina (2012), Bacharel em Administração pela UFSC (2014) e Bacharel em Ciências Sociais - UFSC (2004). É Servidora Técnico-Administrativa em Educação da UFSC.

\section{Andressa Sasaki Vasques Pacheco}

Professora do Departamento de Ciências da Administração da Universidade Federal de Santa Catarina. Professora do Programa de Pós-graduação em Administração e do Programa de Pós-graduação em Administração Universitária.

Doutora em Engenharia e Gestão do Conhecimento - UFSC (2010). Mestre (2007) e Bacharel (2005) em Administração pela UFSC.

\begin{abstract}
Resumo
Esta pesquisa almejou resgatar os fatores críticos de sucesso à manutenção das Comunidades de Prática apresentados por SCHMITT (2012) e verificar suas aderências a um grupo de gestores que possui características preponderantes as de uma Comunidade de Prática. Para tanto, identificou-se, na obra de SCHMITT (2012), 28 fatores críticos à manutenção das Comunidades, e, após este levantamento, aplicou-se um questionário a dez gestores para verificar a aderência dos fatores àquele grupo. A coletividade escolhida para o estudo de caso é constituída por gestores do projeto Aluno Integrado - uma iniciativa do governo federal, com apoio dos governos estaduais e das universidades federais - as executoras do projeto. Respeitando a caracterização da pesquisa quanto aos fins, indica-se que o resultado é de origem aplicada, porquanto possui como base de motivação a resolução de problemas concretos referente à gestão das Comunidades de Prática. Quanto aos meios de investigação, com relação aos objetivos, se classifica como descritiva; e, segundo a fonte de dados, se utilizou o método bibliográfico e o estudo de caso. Como resultando foi possível estabelecer um ranking com os 28 fatores críticos de sucesso à manutenção das Comunidades e o grau de importância que estes se apresentaram ao grupo de gestores do projeto. Ademais, foi possível demonstrar que os fatores apresentados pela literatura possuem aderência à realidade do grupo, alguns em maior e outros em menor escala.
\end{abstract}

Palavras-chave

Comunidades de Prática. Fatores Críticos de Sucesso à Manutenção. Gestão do Conhecimento.

\section{SUCCESS CRITICAL FACTORS FOR THE MAINTANCE PRATICAL COMMUNITIES AN ANALIZYS BASED ON MANAGERS WITH COMMUNITY CHARACTERISTIC}

\begin{abstract}
This research aimed to rescue the success critical factors for the maintenance of Communities of Practice presented by Schmitt (2012) and verify their adherence to a group of managers who have predominant characteristics of a Community of Practice. Therefore, it was identified in the work of Schmitt (2012), 28 critical factors for the maintenance of the Communities, and, after this survey, we applied a questionnaire to ten managers to verify the adherence of the factors to that group. The chosen community for the case study consists of managers of the "Aluno Integrado" project - an initiative of the federal government, with the support of the state governments and the federal universities - the project executors. Respecting the characterization of research as to the purposes, it indicates that the results are from applied origin, therefore its motivation basis to solve concrete problems related to the management of the Communities of Practice. As for the means of investigation with respect to the objectives, it is
\end{abstract}


classified as descriptive; and, according to the source data it was used the bibliographical method and the case study. As a result it was possible to establish a ranking of the 28 success criticalfactors for the maintenance of the Communities and the degree of importance that they presented to the project management group. Furthermore, it was possible to demonstrate that the factors presented in the literature have adherence to the group's reality, some in larger and others smaller scale.

Keywords

Communities of Practice. Success Critical Factors in Maintenance. Knowledge management.

\section{INTRODUÇÃO}

Cunhado no início da década de 90 por Lave e Wenger (1991), o termo "Comunidade de Prática" - CoP - compreende o grupo de pessoas que, mesmo de maneira informal, compartilha conhecimentos (SCHMITT, 2012), motivados pela paixão que sentem pelo tema do domínio da Comunidade (WENGER, 1998a). Forma-se, assim, um espaço social em que os integrantes podem descobrir e desenvolver parcerias de aprendizagem relacionadas a um domínio comum (WENGER; TRAYNER; LAAT, 2011), disseminando conhecimento especializado (WENGER, 1998a).

Alinhando-se a esse entendimento, Zboralski (2009) acrescenta que essas entidades semiformais contam, de regra, com a participação voluntária de seus membros, a qual se dá, sobretudo, por motivações intrínsecas ao indivíduo. São, portanto, verdadeiras formadoras de capital humano, conforme esclarece Santos (2005), e, por isso, reconhecer sua existência e compreender a oportunidade de incentivar a sua criação, segundo reforça o referido autor, não é uma opção, mas sim caminho fundamental para o desenvolvimento e fortalecimento de qualquer instituição.

De um modo geral, referidos ambientes conseguem propiciar benefícios em âmbito individual, coletivo e organizacional, segundo lembram Fontaine e Millen (2004). Elevação das habilidades individuais e do know-how, diminuição de tempo na realização do trabalho e redução de custos e aumento das vendas são bons exemplos das vantagens, de regra, advindas com a valorização das Comunidades de Prática - CoPs - no ambiente organizacional.

Por serem consideradas as oficinas do capital humano e o lugar em que as coisas acontecem (SANTOS, 2005), constituem-se em ferramenta mais eficaz a fim de criar e compartilhar conhecimento, se comparadas aos métodos tradicionais de estruturação das interações e da aprendizagem (VON WARTBURG; ROST e TEICHERT, 2006). Demonstram, assim, ser promissoras vias de geração e disseminação de conhecimento nas instituições 
(SCHMITT, 2012), sendo cruciais para aquelas que reconhecem tal ativo como bem essencial (WENGER, 1998b).

A despeito dos benefícios, Wenger, McDermott e Snyder (2002b) apontam que existe certa dificuldade em estruturá-las. A fim de esclarecer seu ponto de vista, os autores sintetizam a questão na seguinte indagação: como deve ser o design para uma "instituição humana" que, por definição, é espontânea, natural e autodirigível? Na tentativa de solucionar sua própria questão, eles indicam, no que são seguidos por Zboralski (2009), como fatores essenciais ao bom funcionamento das Comunidades: constituição, ainda que em parte, natural; espontaneidade nas participações dos membros; definição dos rumos das atividades pelo próprio grupo.

Como se pode perceber, a identificação dos fatores críticos ao sucesso à manutenção das CoPs possibilita, dentro de um contexto realista (SCARSO; BOLISANI, 2008), que tais ambientes virtuais transformem-se em verdadeiro instrumento de gestão, seja para as organizações mantenedoras, seja para os membros das Comunidades (SCHMITT, 2012).

Ao seu turno, despontam na literatura diversos fatores críticos de sucesso (FCS) relacionados à manutenção das Comunidades, e, Schmitt (2012), por meio de busca sistemática da literatura, apresenta um quadro síntese com os FCS. A partir de tal compêndio, se buscou verificar a aderência de tais fatores ao grupo gestor do projeto Aluno Integrado da Universidade Federal de Santa Catarina.

O projeto em questão faz parte do Programa Nacional de Formação Continuada em Tecnologia Educacional (Proinfo Integrado) - que é uma iniciativa do governo federal em parceria com os governos estaduais e as universidades federais, estas, como executoras do projeto. O objetivo do Proinfo Integrado é promover o uso pedagógico das Tecnologias da Informação e Comunicação nas redes públicas de educação básica.

O grupo de gestor é formado por mestres e doutores que atuam nos âmbitos do ensino, da pesquisa e da extensão na área do ensino a distância, e que, após análise de suas características, se comparadas as conferidas às Comunidades por Wenger e Snyder (2001), possui em seu cerne elementos preponderantes de uma CoP.

Em meio aos pontos acima apresentados, surge a pergunta que guiou esta pesquisa: os fatores críticos de sucesso apresentados pela literatura à manutenção das Comunidades de Prática possuem aderência a um grupo de gestores com características preponderantes as de uma Comunidade de Prática? 
O objetivo geral deste estudo é Analisar a aderência dos fatores críticos à manutenção das Comunidades de Prática apresentados por Schmitt (2012) no grupo de gestores do projeto Aluno Integrado.

Para que se atinja o objetivo geral, foram estabelecidos os seguintes objetivos específicos: Apresentar os fatores críticos de sucesso à manutenção das Comunidades de Prática elencados na obra de Schmitt (2012); Caracterizar o grupo em análise como uma comunidade de prática; Identificar os fatores críticos à comunidade de prática presentes no grupo em estudo.

\section{COMUNIDADES DE PRÁTICA}

As Comunidades de Prática, na visão de Mcnabb (2007), apresentam-se como grupos de indivíduos que, a fim de compartilhar o que eles sabem ou, mesmo, o que desconhecem, agregam-se em alguma situação social, mediante a afinidade de interesses, conhecimentos, habilidades, preocupações ou treinamento semelhantes. Até por isso, Wenger, Trayner e Laat (2011) centram sua definição no termo "parceria de aprendizagem", ao defender que, nas CoPs, pessoas, transitando em um mesmo domínio de conhecimento, observam a validade do ato de compartilhar e aprender com o outro.

Cria-se um ambiente comunitário (espaço social) em que os participantes têm a possibilidade de descobrir e promover parcerias formais ou informais de aprendizagem relacionadas a um domínio comum (WENGER; TRAYNER; LAAT, 2011). A mistura do aprendizado individual e coletivo no intuito de construir uma prática compartilhada é característica principal da ferramenta - que se torna então um mecanismo de ajuda (WENGER; TRAYNER; LAAT, 2011) -, cujos membros, em regra, possuem interesse em aplicar na prática os conhecimentos advindos por meio da interação na CoP (WENGER; SNYDER, 2000).

O debate acerca das Comunidades de Prática, inclusive, não é novo, pois já existiam na antiguidade, nos tempos da Grécia clássica. As “corporações” de serralheiros, pedreiros, oleiros e outros artesãos mantinham uma finalidade social (adoravam as mesmas divindades e comemoravam juntos os feriados sagrados) e comercial (treinavam aprendizes e divulgavam as inovações) (WENGER; SNYDER, 2000). Esta última finalidade, por sua vez, foi a que se tornou o foco por ocasião dos anos que se seguiram, no período da Idade Média (WENGER; SNYDER, 2000). 
Muito embora seja uma ferramenta antiga, as CoPs, tal qual hoje são concebidas, somente tiveram ampla divulgação a partir de textos produzidos por Lave e Wenger em 1991 (SCHMITT, 2012). Atualmente, distanciam-se e diferenciam-se do espírito que as criou quando se verifica que, no primeiro momento, eram compostas por indivíduos que trabalhavam por conta própria, enquanto agora existem dentro de organizações (WENGER; SNYDER, 2000).

No interior dessas, as pessoas disseminam conhecimento especializado e sentem paixão pelo tema do domínio da Comunidade (WENGER, 1998a). Da união a partir de um conjunto de questões comuns, nos dizeres de Wenger (2000), há compartilhamento do conhecimento, hábil a proporcionar uma competência crítica para o sucesso das instituições que as adotam.

Justamente por essa característica é que as CoPs são percebidas como oficinas do capital humano e o lugar em que as coisas acontecem, essenciais ao êxito organizacional (SANTOS, 2005). Nos últimos tempos, assim, sua importância apenas aumentou, provando-se indispensável que se reconheça sua existência e se entenda a necessidade de incentivar sua criação, sob pena de se tolher a formação e desenvolvimento do aludido capital (SANTOS, 2005).

\subsection{Características}

Wenger (1998b) afirma que a maioria das Comunidades de Prática existe sem o conhecimento da organização. Esse fenômeno se justifica, na visão do autor, porque referidos grupos devem existir espontaneamente ou pelo mero estímulo, e não imposição, das organizações.

O fator espontaneidade surge, nesse contexto, como forte característica para o êxito na sobrevivência da CoP, uma vez que há melhor coesão num grupo de pessoas que, voluntariamente, cooperam de forma direta, ensinando umas às outras e explorando juntas o novo assunto (SANTOS, 2005). Em função disso, Santos (2005), na linha de Wenger (1998b), é categórico ao afirmar também que a estruturação das Comunidades de Prática deve ocorrer por consenso dos interessados, e não por decreto da organização.

Essa, porém, não necessariamente deve ficar neutra e sem participação no desenvolvimento das CoPs (WENGER, 1998b). Para o autor, tomado o cuidado a fim de não sufocá-las, algumas precisam ser "semeadas e cuidadas", visto que, muitas vezes, o apoio 
institucional pode assegurar o crescimento de determinados grupos, em especial daqueles que possam vir a se mostrar vitais para o bom desempenho organizacional.

Segundo ainda Wenger (1998b), esse estímulo deve levar em consideração os seguintes pontos:

a) Criar sintonia com práticas existentes na organização: se, geralmente, o conhecimento que as organizações precisam já está no seu próprio interior, indispensável promover CoPs que aproveitem esse potencial;

b) Harmonizar os sistemas de reconhecimento às CoPs: existem elementos do ambiente organizacional que podem favorecer ou obstar a formação de Comunidades, como, por exemplo, sistemas de recompensa, processos de trabalho, cultura corporativa etc. $\mathrm{O}$ equilíbrio desses fatores é indispensável para gerar espontaneidade e satisfação em participar do referido grupo;

c) Respaldar a participação dos membros: é necessário que as organizações reservem um tempo (período) a fim de que os membros participem das atividades comunitárias, inclusive, se possível, com local específico para tanto;

d) Alinhar o contexto estratégico: a ponderar que o conhecimento está vinculado às estratégias de negócio, inegável que as Comunidades possuem valor estratégico. Essencial, portanto, definir o que é conhecimento e quais práticas uma determinada atividade exige, bem como ficar atento para o que as CoPs trazem como possíveis direções estratégicas, isto é, conhecimento extraído da prática diária.

e) Conceder suporte: embora autossuficientes, referidos grupos podem ser beneficiados por recursos fornecidos pela organização, como, por exemplo, instalações para as reuniões e tecnologia de comunicação. É possível a formação de um grupo apoiador, composto por funcionários de diversos setores da empresa, que disponibilizará o suporte necessário às CoPs, e, principalmente, cuja existência demonstrará que a organização valoriza a iniciativa de participação dos membros e também os trabalhos que aquelas desenvolvem.

Dentro da instituição, as CoPs podem existir em um departamento ou entre departamentos. Pode-se cogitar, até mesmo, que venha a ser criada entre organizações, a depender dos objetivos traçados para cada grupo. Isso explica, na visão da APO (2010), a variedade de CoPs existentes, cujo tamanho, segundo apontou, oscila entre duas, três ou milhares pessoas, podendo ser homogênia ou heterogênia, no que se tange ao conhecimento dos membros 
sobre o domínio em discussão. Ainda, podem ser presenciais, mas há, inclusive, aqueles grupos cuja interação dos membros é basicamente virtual, denominados VCoPs - Comunidades Virtuais de Prática (VON WARTBURG; ROST; TEICHERT, 2006).

Por tudo até aqui relatado, percebe-se que, sob o ponto de vista estrutural (WENGER, 1998a; WENGER; SNYDER, 2000; WENGER; MCDERMOTT; SNYDER, 2002a), as CoPs possuem três elementos básicos: a) a comunidade, que se traduz num grupo de pessoas que interage; b) o domínio, que determina a área de interesse ou atividade comum aos membros; e c) a prática, compreendida como o fazer determinada atividade com especialidade, com perícia.

Em função desse quadro estrutural, deve-se cuidar, conforme alertam Wenger e Snyder (2001), para não confundir as Comunidades de Prática com outras formas de organização grupal. Pensando nisso, mencionados autores enumeraram características que entendem ser específicas das CoPs, de forma distingui-las dos demais grupos, as quais são apresentadas abaixo:

Quadro 1 - Comparação das CoPs com outras formas de organização grupal

\begin{tabular}{|c|c|c|c|c|}
\hline Grupo & Qual é o objetivo? & Quem participa? & O que tem em comum? & Quanto tempo dura? \\
\hline $\begin{array}{c}\text { Comunidade de } \\
\text { Prática }\end{array}$ & $\begin{array}{c}\text { Desenvolver as } \\
\text { competências dos } \\
\text { participantes; gerar e } \\
\text { compartilhar } \\
\text { conhecimentos. }\end{array}$ & $\begin{array}{c}\text { Participantes que } \\
\text { se auto-selecionam } \\
\text { (e integrantes que } \\
\text { avaliam a } \\
\text { adequabilidade do } \\
\text { associado } \\
\text { pretendente) }\end{array}$ & $\begin{array}{c}\text { Paixão, compromisso e } \\
\text { identificação com os } \\
\text { conhecimentos } \\
\text { especializados do grupo. }\end{array}$ & $\begin{array}{c}\text { Enquanto houver } \\
\text { interesse em manter o } \\
\text { grupo. }\end{array}$ \\
\hline $\begin{array}{c}\text { Grupo de trabalho } \\
\text { formal }\end{array}$ & $\begin{array}{c}\text { Desenvolver um } \\
\text { produto ou prestar um } \\
\text { serviço. }\end{array}$ & $\begin{array}{c}\text { Qualquer um que } \\
\text { se apresente ao } \\
\text { gerente do grupo. }\end{array}$ & $\begin{array}{c}\text { Requisitos do trabalho e } \\
\text { metas em comum. }\end{array}$ & $\begin{array}{c}\text { Até a próxima } \\
\text { reorganização. }\end{array}$ \\
\hline $\begin{array}{c}\text { Equipe de projeto } \\
\text { Rede informal }\end{array}$ & $\begin{array}{c}\text { Realizar determinada } \\
\text { tarefa. }\end{array}$ & $\begin{array}{c}\text { Colaboradores } \\
\text { escolhidos por } \\
\text { gerentes seniores. }\end{array}$ & $\begin{array}{c}\text { As metas e pontos } \\
\text { importantes do projeto. }\end{array}$ & Até o final do projeto. \\
\hline informações & $\begin{array}{c}\text { Amigos e } \\
\text { conhecidos do } \\
\text { meio empresarial. }\end{array}$ & Necessidades mútuas. & $\begin{array}{c}\text { Enquanto as pessoas } \\
\text { tiverem motivo para } \\
\text { manter contato. }\end{array}$ \\
\hline
\end{tabular}

Fonte: Wenger e Snyder (2001)

Em relação à participação dos membros, Wenger, McDermott e Snyder (2002b) destacam a existência, basicamente, de três níveis: núcleo, ativo e periférico. No primeiro, constituído de $10 \%$ a $15 \%$ do total de pessoas, há a ativa participação, movendo a Comunidade na tarefa da aprendizagem. Já no segundo, composto de $15 \%$ a $20 \%$ do aludido total, estão aqueles que 
assistem às reuniões com regularidade e participam de alguns fóruns, no entanto sem a intensidade do núcleo. Por fim, no último, é onde se encontra o maior número de integrantes da comunidade, que, por sua vez, raramente participam e, por isso, ficam apenas observando as interações entre os membros do núcleo e do ativo. Referidos autores relatam ainda a existência de um "quarto grupo", que está fora dos três principais níveis, rodeando a Comunidade, e possui interesse por ela, que são os clientes e as CoPs que partilham do mesmo domínio.

Completando o esboço de características, Wenger (1998b) ensina ainda que as Comunidades, fundamentais no papel de disseminação do conhecimento, exercem as seguintes funções:

- “Administradoras" de competências: como os membros da CoP discutem questões essenciais relativas ao contexto interno e/ou externo de sua organização, estão, desse modo, motivados a buscar alternativas aos problemas apresentados, criando um ambiente de vanguarda;

- "Espaços de identidade": o domínio que une os integrantes auxilia na manutenção do foco, separando assuntos secundários do principal, o que possibilita, por consequência, que sejam alcançados, mais rapidamente, os respectivos resultados;

- "Nós" para o intercâmbio e interpretação de informações: os membros sabem o que é relevante para se comunicar e como as informações devem ser apresentadas a fim de que sejam úteis. Cria-se um canal ideal voltado a obter informações em movimento, tais como dicas e retornos de ações efetuadas pela instituição;

- Armazenadoras de conhecimento das "vivências" dos profissionais: guardam aspectos tácitos do conhecimento, permitindo que ele não se perca com o tempo e que seja compartilhado inclusive pelos recém-chegados na organização.

\subsection{Aprendizagem nas Comunidades de Prática}

Wenger (2012) defende que a prática possui vida própria, traduzindo-se em algo que se produz, em um movimento de negociação ativa e dinâmica dos significados, ao longo do tempo por aqueles que a ela se dedicam. Os esforços externos para moldá-la, segundo afirma, são inúteis, visto que prevalecem os significados atribuídos pelos envolvidos. 
Isto é, mesmo quando em conformidade com normas externas, as pessoas reproduzem práticas que espelham seus próprios engajamentos com a situação. Por isso, a prática nunca é simplesmente a sua produção ou execução, é uma resposta a elas, oriunda de uma negociação ativa dos significados, razão pela qual não podem ser classificadas segundo um modelo, uma instituição ou outra prática (WENGER, 2012).

Foi com base nessa premissa que Lave e Wenger (1991) desenvolveram a Teoria da Aprendizagem Situada, na qual afirmam que a aprendizagem consiste num processo decorrente da participação social e, por conseguinte, o envolvimento com a prática se mostra o pressuposto para a sua efetivação. Referida teoria possui base em cinco princípios:

$\mathbf{1}^{\mathbf{0}}$. A inseparabilidade do conhecimento e da prática;

$\mathbf{2}^{\mathbf{0}}$. A inseparabilidade da participação nas Comunidades e do processo de aprendizagem;

$3^{\text {. }}$. O encorajamento à participação nas Comunidades, pois a habilidade de compartilhar em um ambiente comunitário gera o potencial para a aprendizagem;

$4^{\mathbf{0}}$. A aprendizagem como fenômeno social, na qual é possível que as comunidades sociais concretizem o aprendizado dos indivíduos que delas participam;

$\mathbf{5}^{\mathbf{0}}$. A integração do conhecimento nas Comunidades, ambiente em que se compartilham valores, crenças e modos de fazer as atividades.

A prática, portanto, gera conhecimento a ser criado no núcleo ou nas interações no entorno das CoPs, o que, por sua vez, se apresenta, segundo Wenger (1998b), modo de alavancar a aprendizado em tais ambientes sociais. Nestes, a depender dos níveis de interação, o sistema de aprendizado assume diferentes formas, da qual a captura ocorre por três maneiras: alinhamento, engajamento e imaginação (WENGER, 1998a; 2000).

Na primeira, afirma-se que as atividades locais devem ser alinhadas aos demais processos, independentemente do envolvimento individual na questão, de forma a compartilhar conhecimento e, por consequência, ganhar maior eficiência. Na segunda, o empenho do trabalho em grupo proporciona o aprofundamento da experiência ao ponto de se aprender o que se pode fazer e quais serão as reações das respectivas ações. Na última, ao surgir a necessidade de se construir uma imagem da $\mathrm{CoP}$, de seus participantes e, mesmo, do mundo, abre-se espaço à autocrítica e à descoberta de novas oportunidades. 
A relevância da interação em todos os níveis é defendida por Wenger, McDermott e Snyder (2002b), que apregoam inclusive a essencialidade do periférico, pois, segundo afirmam, as pessoas que estão nos bastidores, com frequência, não são tão passivas quanto se acredita. É que, conquanto não participem de debates com o núcleo ou com o grupo ativo, realizam discussões com outros colaboradores da organização e, assim, ganham e constroem novas percepções de determinados temas. Ao partir disso, Schmitt (2012) conclui que as CoPs geram conhecimento em todas as esferas de participação, ainda que com gradações diferenciadas, sendo fundamentais por sua contribuição à organização e ao membro.

O conhecimento ainda pode ser mais bem fomentado quando se atenta, nos dizeres de Wenger (1998a), para a necessidade de se fortalecer e equilibrar os quatro pares de dimensões do design relacionados à aprendizagem nas Comunidades. São elas:

- Identificação/negociação: a primeira consiste no ato de adesão de uma pessoa por algo que lhe faz sentido, enquanto a outra se liga ao processo de se negociar o valor para uma dada situação. É responsável por criar a identidade individual e a comunitária;

- Projetada/emergente: se "a prática não é o resultado do projeto, mas sim uma resposta a ele" (WENGER, 1998a, p. 233, tradução nossa), há seguramente uma dualidade a ser considerada entre o que foi projetado e o que emergiu na prática, a gerar aprendizado;

- Participação/reificação: participar envolve formar conexão com outros, formando a identidade do grupo, enquanto reificar se significa dar forma à experiência, cristalizar e realizar ideias dando concretude a conceitos abstratos. A tensão do seu diálogo propicia a existência de dinamicidade no processo de aprendizagem, a ponto de renegociar significado da experiência pretérita (WENGER, 2012);

a) Local/global: ambos os contextos contribuem para o crescimento da CoP: No primeiro, cuida-se de questões próprias dos membros, ao passo que, no segundo, se alarga a visão dos participantes ao se analisar o que ocorre fora das suas organizações.

Wenger (2000; 2012), no entanto, alerta que o debate sobre as CoPs não pode ser efetuado de forma romanceada, isto é, sem que se perceba eventuais desvantagens no método. Explica o autor que, para além dos benefícios, as Comunidades podem, também, aprisionar a aprendizagem sob determinadas óticas. Para tanto, seria indispensável a avaliação das seguintes perspectivas, 
que devem obrigatoriamente trabalhar juntas para o êxito da CoP: a) enterprise; b) repertoire; e c) mutuality.

Na primeira, considera-se o nível de energia que se dispõe ao aprendizado, visto que é essencial reconhecer e lidar com lacunas do conhecimento, de modo a permanecer aberto às oportunidades e novos temas e direções emergentes. Na segunda perspectiva, avalia-se a capacidade de autoconhecimento e autocrítica, fundamental à descoberta de novas possibilidades e o descarte de premissas e padrões ultrapassados. Na última, verifica-se a mutualidade entre os participantes, pois a interação será maior quanto maior for a confiança entre os membros.

No que tange a possíveis limitações das CoPs, Li, Zhu e Lai (2010) ensinam que a difusão do conhecimento de "alta frequência" (vários contatos num curto período de tempo) faz com que todos se tornem, em termos de conhecimento, semelhantes e uniformes. Pensamentos e ideias tornam-se homogêneos, e os integrantes não podem, por vezes, desenvolver o seu potencial a fim de inovar no conhecimento, isto é, não progridem. Por isso, referidos autores sugerem o contato de moderada frequência, permitindo aos membros desenvolver, entre as reuniões da CoP, seu potencial e, desta forma, agregando mais a esta.

Muito embora possam existir dificuldades, o processo de aprendizagem por meio das Comunidades de Prática mostra-se como uma ótima alternativa, pois "permite acelerar e facilitar a disseminação do conhecimento no grupo, o que, por sua vez, traz benefícios individuais, organizacionais e para a própria Comunidade" (SCHMITT, 2012, p. 60).

\subsection{Desenvolvimento de CoPs}

Para as Comunidades de Prática, a etapa inicial de sua criação é seguramente crítica. Será o momento em que se estabelecerá a confiança entre os membros, que, por sua vez, avaliarão o potencial de sua participação (ARDICHVILI et al. 2003). Essas primeiras interações, que antecedem o estabelecimento do núcleo, constituem-se em fator chave, porquanto determinam a permanência ou não no ambiente comunitário (WENGER; MCDERMOTT; SNYDER, 2002b).

Em seguida, a capacidade de gerar entusiasmo suficiente a atrair novos membros será crucial, conforme Wenger, McDermott e Snyder (2002b), para que a CoP seja bem sucedida a longo prazo. Até por isso, novamente retomam os autores a ideia de voluntariedade na adesão, muito embora isso, por si, não garanta também o êxito do grupo, pois, segundo explicam, muitas 
Comunidades, de formação espontânea, não crescem além de uma rede de amigos, já que não conseguem atrair participantes suficientes.

Os membros da CoP, portanto, devem guardar um sentimento de vivacidade, circunstância que, nos dizeres de Wenger, McDermott e Snyder (2002b), implica definir e delimitar o design para uma "instituição humana", que, por definição, é natural, espontânea e autodirigível. Para tanto, os mencionados autores apontam sete princípios para a construção de espaços propícios à Comunidade estabelecer a sua própria direção, gerando energia com a finalidade de mantê-la. São eles:

a) Foco no valor: o valor proporcionado pela $\mathrm{CoP}$ à organização, aos grupos que os participantes integram e aos seus próprios membros é fator vital, pois indicará a importância que se dá ao ambiente comunitário e, por consequência, à sua existência. Muito embora, no início, o valor agregado seja de difícil mensuração, as discussões em torno do tema auxiliarão para que a Comunidade entenda sua relevância, independentemente do fato de o valor mudar durante a existência comunitária;

b) Harmonizar familiaridade com excitação: as CoPs tornam-se espaços em que as pessoas possuem liberdade para pedir conselhos, partilhar opiniões e "ousar", ou seja, cria-se um espaço de conforto entre os membros. Sair dessa zona - o que pode ocorrer com a presença em conferências, feiras e workshops - estimula o pensamento criativo e novo, encontrando na harmonização entre conforto e a emoção da novidade a junção necessária à manutenção proveitosa da dinâmica comunitária;

c) Design das Comunidades: projetar o design, no caso, dada a organicidade inerentes às CoPs, reside muito mais na preocupação com a subsistência comunitária do que necessariamente com sua criação. Atitudes que não sufoquem as comunidades e não estabelecer metas que não emergiram delas são decisivos nessa questão. Geralmente, para essa situação, a atuação gradual e inteligente do coordenador da CoP será fundamental para o êxito da proposta;

d) Ser receptivo às experiências de outras Comunidades: a observação de outras comunidades (da mesma organização ou externas a ela) pode resultar na obtenção de saídas para os problemas vivenciados. Além disso, possibilita a interação com outras pessoas, com formação de novas redes de especialistas e a identificação de capacidades latentes no grupo, transformando os membros da CoP em verdadeiros agentes de mudança; 
e) Estabelecer um ritmo: Wenger, Mcdermott e Snyder (2002b), comparando o ritmo da Comunidade a uma batida cardíaca, afirmam que, se esta é muito rápida, o grupo sente falta de ar e as pessoas param de participar, visto que estão sobrecarregadas. Quando a batida é demasiadamente pausada, a CoP sente-se lenta. Por isso, o ritmo é o indicativo mais forte da vitalidade da Comunidade (SCHMITT, 2012), devendo-se almejar, ao máximo, a equalização certa em cada etapa.

f) Motivar a participação de membros de níveis diferentes (núcleo, ativo e periférico): para tanto, forçoso que as atividades comunitárias proporcionem a impressão de que todos são membros plenos. Pode-se, por exemplo, oportunizar interações semiprivativas mediante salas de discussões privadas na internet. Com isso, além de fomentar a participação de membros periféricos, criam-se oportunidades para os membros ativos assumirem papéis de liderança (em projetos de compromisso e tempo mínimo).

g) Desenvolver espaços públicos e privados: a troca de experiência entre espaços públicos e privados é por demais proveitosa ao grupo (enriquecimento mútuo), a exigir do respectivo coordenador a criação de um espaço privado entre as reuniões, no qual os participantes possam discutir seus problemas técnicos e vinculá-los com as possíveis soluções, dentro ou fora da Comunidade. Os encontros privados, por sua vez, tornam-se o substrato para as reuniões públicas, visto que, no momento da reunião com o grupo maior, os membros já compartilharam suas dúvidas/ideias, o que proporciona uma discussão mais avançada sobre as questões postas no evento público, tornando mais proveitosas as discussões.

No desenvolvimento das CoPs, McDermott (2000) sustenta a necessidade de superação de obstáculos que dificultam as conexões entre as pessoas, especialmente porque essas interações visam à criação de relacionamentos de mútua confiança no ambiente comunitário. Nesse cenário, aludido autor aponta quatro dimensões de dificuldades à manutenção de Comunidades, que são os desafios:

a) técnico: a tecnologia colaborativa da Comunidade precisa ser de fácil manuseio e compreensível a todos os membros;

b) individual: garantir-se um sentimento de segurança a fim de que os participantes compartilhem suas ideias/dúvidas/percepções com os outros;

c) à gestão: o domínio deve girar em torno de temas centrais ao negócio da empresa, porquanto, se os resultados não forem impactantes para a organização, possivelmente a CoP não 
sobreviverá. Além disso, a respeitabilidade do coordenador - que deve deter conhecimento técnico sobre o domínio e, sobretudo, habilidade para conectar as pessoas -, cultura corporativa propícia às CoPs e a reserva de tempo para a participação nas atividades comunitárias são pontos delicados e incluídos no presente desafio.

d) à comunidade: fundamental que se sustente a energia da Comunidade, envolvendo pessoas que possuam elevado conhecimento a respeito do domínio, pois nisso, em muito, reside legitimidade da CoP. A criação de espaços em que os indivíduos possam ter contato face a face e a obtenção de suporte da organização também são questões que não podem passar despercebidas.

Por fim, o desenvolvimento das CoPs depende do elemento agregador, qual seja, o sentimento de identidade com o grupo e com o que é compartilhado em seu interior. Dalkir (2005) explica que algo simples, como boletins on-line ou em papel, pode proporcionar a espinha dorsal para a Comunidade se desenvolver, pois um senso de Comunidade poderá emergir quando os participantes lerem o mesmo texto, artigo ou um mesmo anúncio.

\subsection{Fatores Críticos de Sucesso à manutenção de CoPs}

Neste ponto, é importante reconhecer que o estudo de tal temática não está completo sem a diferenciação entre os pontos fortes e fracos à manutenção das CoPs. Conforme Santos (2010), os pontos fortes e as oportunidades são elementos que potencializam o desenvolvimento de tais entidades, desde que sejam aproveitados satisfatoriamente. De outro modo, Santos (2010) complementa dizendo que os pontos fracos e as ameaças são aqueles que tornam as CoPs vulneráveis e afetam negativamente as atividades que capacitam para o conhecimento.

Demonstrada a diferenciação, e seus correspondentes papéis no tema em análise, interessante se faz a apresentação dos fatores que correspondem a cada uma dessas duas categorias, isso porque referida classificação é de relevância no contexto da gestão das CoPs. Para tanto, apresenta-se a seguir o quadro-referência de Schmitt (2012), em que 28 fatores críticos de sucesso à manutenção de Comunidades de Prática são descortinados. 


\section{Quadro 2- Quadro-referência dos 28 FCS à manutenção de CoPs, conforme Schmitt (2012)}

\section{Fatores Críticos de Sucesso à manutenção de CoPs}

1 - A demonstração pública, por parte dos gestores, da importância das atividades das Comunidades para a organização eleva a autoestima dos membros, o que favorece as suas participações.

2 - As organizações podem propor CoPs aos seus colaboradores, no entanto não devem impor critérios e processos estruturados. A imposição de normas retira da $\mathrm{CoP}$ a sua autodeterminação.

3 - Somado à falta de tempo, o conflito de prioridades entre o papel de colaborador da organização e o de membro da $\mathrm{CoP}$ pode reduzir a motivação para a participação em CoPs.

4 - Comunidades com foco local agem em questões específicas dos membros e, dessa forma, aumentam os benefícios diretos a eles.

5 - As informações sobre a Comunidade devem ser divulgadas dentro da organização como meio de não segregar possíveis interessados, e mesmo de evitar animosidade entre os não membros e os membros (sentimentos como inveja, desconfiança).

6 - Excesso de trabalho na organização influencia os membros a declinarem das Comunidades.

7 - As CoPs devem ser criadas em torno de temas centrais ao sucesso do negócio da organização.

8 - Os membros necessitam de liberdade para expressar suas opiniões e dúvidas. Mecanismos de controle sob a CoP baseados em autoridade impedem as contribuições espontâneas.

9 - O papel do líder assume características baseadas em diretrizes como influência respeito, estímulo intelectual e orientação.

10 - As CoPs necessitam de um "fator" agregador a fim de estimular a participação dos membros, seja um membro respeitado pelos demais para atuar como coordenador, seja um grupo gestor.

11 - O princípio da autodeterminação deve ser preservado, uma vez que ele possibilita a sustentabilidade das Comunidades.

12 - As CoPs necessitam da presença de um líder atuante para o seu sucesso.

13 - Encontros face a face devem ser fomentados nas CoPs. Tais interações são fundamentais para a construção do sentimento de confiança entre os membros.

14 - O suporte da Organização é importante para a manutenção da Comunidade.

15 - Realização de avaliações formais dos objetivos, custos e resultados das CoPs é importante para sua manutenção. 
Fatores críticos de sucesso à manutenção de Comunidades de Prática: análise sob a ótica de um grupo de gestores com características preponderantes as de uma Comunidade

\begin{tabular}{|l|}
\hline \multicolumn{1}{|c|}{ Fatores Críticos de Sucesso à manutenção de CoPs } \\
\hline $\begin{array}{l}16 \text { - Os resultados das Comunidades levam tempo para se evidenciarem, assim é necessário } \\
\text { aguardar por seus benefícios. }\end{array}$ \\
\hline 17 - Estabelecer de forma clara e objetiva o domínio da CoP, para ciência dos membros e \\
da organização quanto ao seu conteúdo.
\end{tabular}

Fonte: Elaborado pelas autoras (2014), a partir de Schmitt (2012).

\section{PROCEDIMENTOS METODOLÓGICOS}

A pesquisa possui cunho aplicado, ou seja, é a modalidade, segundo Vergara (2007), em que os conhecimentos adquiridos são utilizados para aplicação prática voltados para a resolução de problemas concretos. Nesta pesquisa o objetivo é verificar o grau de aderência dos fatores críticos de sucesso apresentados pela literatura para um grupo de gestores de um projeto de curso a distância.

A pesquisa também se classifica como descritiva, por ter como um dos seus focos a descrição das características de determinada população ou fenômeno, e por estabelecer relações 
entre variáveis e não ter o compromisso de explicar os fenômenos que descreve, mas o de servir de base para tal explicação (VERGARA, 2007; GIL, 2010).

Os procedimentos adotados para esta investigação foram o bibliográfico e o estudo de caso.

Assim, para esta pesquisa, a coleta foi realizada por meio bibliográfico e pelo instrumento de pesquisa questionário.

As fontes utilizadas para a coleta bibliográfica foram livros, teses, dissertações, anais de encontros científicos, sítios na internet e periódicos científicos.

Por meio do estudo bibliográfico obteve-se um rol de 28 fatores críticos de sucesso à manutenção de CoPs, extraído da obra de Schmitt (2012). Como forma de avaliar a aderência dos FCS apresentados pela autora à realidade de uma Comunidade de Prática, foi aplicado um questionário a um grupo com características preponderantes as de uma CoP. Informa-se que o estudo de Schmitt (2012) extraiu os FCS exclusivamente da literatura não tendo sido observados, pela autora, em CoPs reais.

O questionário foi respondido por 10 pessoas, integrantes do Projeto Aluno Integrado, que atuam como gestoras. O grupo em sua totalidade é formado por 12 gestores.

Com a finalidade de possibilitar a criação de um ranking que demonstrasse os FCS com maior relevância ao grupo de gestores, foi atribuído, a partir da escala Likert, pesos às alternativas de respostas. O quadro abaixo presta-se a divulgar os pesos atribuídos as alternativas.

Quadro 3 - Alternativas e pesos da escala Likert

\begin{tabular}{|l|c|}
\hline Alternativas da escala Likert & Pesos \\
\hline Discordo totalmente: & -2 (dois negativos) \\
\hline Discordo: & -1 (um negativo) \\
\hline Nem concordo nem discordo: & 0 (zero) \\
\hline Concordo: & 1 (um positivo) \\
\hline Concordo Totalmente: & 2 (dois positivos) \\
\hline
\end{tabular}

Fonte: elaborado pelas autoras (2014).

A considerar uma das características, segundo a fonte de dados, como um estudo bibliográfico, verificou-se a importância em sistematizar a forma de leitura dos dados e informações constantes nos trabalhos que deram embasamento teórico para esta investigação.

A partir das leituras analítica e interpretativa da obra de Schmitt (2012), identificou-se os 28 FCS à manutenção das Comunidades de Prática apontados pela autora. O quadro final, com os 
fatores, originou de ampla pesquisa a artigos científicos nacionais e internacionais, em que a técnica da busca sistemática da literatura foi empregue.

Quanto à validação dos FCS encontrados na literatura, utilizou-se da ferramenta de pesquisa questionário. Este se mostrou útil, pois possibilitou verificar a aderência dos fatores a um caso real de um grupo com características preponderantes as de uma CoP.

\section{ESTUDO DE CASO}

\subsection{O PROJETO ALUNO INTEGRADO}

O projeto Aluno Integrado é parte do Programa Nacional de Formação Continuada em Tecnologia Educacional (Proinfo Integrado). O programa foi criado pela Portaria $n^{\circ}$ 522/MEC, de 9 de abril de 1997, com o nome de Programa Nacional de Informática na Educação (ProInfo). Em 2007, passou a ser denominado Programa Nacional de Tecnologia Educacional (UFSC, 2010).

Conforme declarado no sítio eletrônico do Aluno Integrado/UFSC, “o objetivo do Proinfo Integrado é promover o uso pedagógico das Tecnologias da Informação e Comunicação nas redes públicas de educação básica" (UFSC, 2010). Quanto à operacionalização, o Programa fornece às escolas os computadores, os recursos digitais e os conteúdos. Já os estados, o Distrito Federal e os municípios são responsáveis por proporcionar os laboratórios e capacitar professores e estudantes para o uso dos computadores e das tecnologias.

O público alvo desse projeto são estudantes a partir do nono ano, matriculados em instituições públicas federais, estaduais ou municipais. O curso possui a carga horária de 180 horas com duração de aproximada de cinco meses, e é ofertado por meio do ambiente virtual de aprendizagem (AVA) e-Proinfo. O ambiente foi desenvolvido especificamente para o aprendizado de informática a distância, e, neste, os estudantes aprendem conceitos centrais dessa modalidade educacional, história da informática, hardware (equipamentos), manutenção de computadores e sistemas operacionais (UFSC, 2014).

Em 2009, foi realizado um projeto piloto com a participação de 2.700 alunos indicados pelos coordenadores do Proinfo Integrado e pela União dos Dirigentes Municipais de Educação 
(Undime) em todos os estados. O curso fomentou a discussão sobre as Tecnologias da Informação e Comunicação nas escolas, capacitou os estudantes para o uso e gerenciamento dos laboratórios de informática, além de contribuir para a qualificação dos alunos frente ao mercado de trabalho (UFSC, 2010).

Em 2010 foram abertas 70.000 vagas em todo o Brasil. A Universidade Federal de Santa Catarina (UFSC) foi responsável pela formação de 15.000 estudantes distribuídos entre os estados do Mato Grosso do Sul, Paraná, Santa Catarina e Rio Grande do Sul. Nas edições dos anos de 2011 e 2012, a UFSC não fez parte do projeto, e a Instituição responsável pela disponibilização do curso foi a Universidade Federal de Goiás.

Já para o ano de 2013, a UFSC foi novamente convidada a fazer parte do programa, mas, desta vez, com uma modificação na cobertura geográfica de seus alunos - agora, apenas responsável pelo estado de Santa Catarina. Nesta edição, uma Universidade Federal de cada um dos estados da federação foi convidada a participar, e desse modo, a UFSC redimensionou o público alvo do curso. Foram selecionados 4800 estudantes para a edição de 2013.

A equipe era formada por seis gestores do projeto, seis orientadores de tutoria, duas secretárias, e em média cento e onze tutores a distância. Como resultado para esta edição, concluíram com êxito o curso 893 alunos.

Para este ano de 2014, o número de vagas foi diminuído pelo Ministério da Educação para 2.400 vagas, pelo motivo de cortes no orçamento para a Educação Básica, e, por consequência, para este projeto. Como a relação de alunos influi no número de pessoas que atuam no projeto, a equipe foi reduzida para quatro orientadores de tutoria, sessenta e três tutores a distância, e seis gestores (núcleo que não houve mudança se comparado com o de 2013).

Por fim, para o ano corrente, algumas mudanças foram planejadas para a execução do curso, sobretudo ações que visam à diminuição da evasão dos alunos, mas de forma geral, as diretrizes permanecem as já aplicadas nas edições anteriores do Projeto.

\subsection{ANÁLISE DE DADOS}

Os fatores que diferenciam as Comunidades de Prática dos demais grupos dizem respeito aos seus objetivos, aos participantes, ao que os membros têm em comum e à duração dessas comunidades, grupos, equipes e redes. 
Como forma de melhor visualizar as características do grupo gestor do projeto e classificá-lo, se comparado à classificação propostas por Wenger e Snyder (2001), fez-se o mesmo exercício proposto pelos autores, mas, agora, para a grupo gestor do projeto sob análise.

Quadro 4 - Características do Grupo Gestor do Aluno Integrado

\begin{tabular}{|c|c|c|c|c|}
\hline Grupo & Qual é o objetivo? & Quem participa? & O que tem em comum? & Quanto tempo dura? \\
\hline $\begin{array}{l}\text { Grupo gestor do } \\
\text { projeto Aluno } \\
\text { Integrado }\end{array}$ & \begin{tabular}{|} 
Auxiliar os alunos \\
participantes do \\
projeto no processo de \\
ensino/aprendizagem a \\
cerca das Tecnologias \\
da Informação e \\
Comunicação.
\end{tabular} & $\begin{array}{c}\text { Os coordenadores } \\
\text { se autosselecionam } \\
\text { e possuem, para } \\
\text { além do } \\
\text { compromisso } \\
\text { profissional, laços } \\
\text { de amizade. }\end{array}$ & $\begin{array}{c}\text { O grupo de } \\
\text { coordenadores é formado } \\
\text { por doutores e mestres } \\
\text { que atuam no ensino, na } \\
\text { pesquisa e na extensão } \\
\text { com foco no ensino a } \\
\text { distância. }\end{array}$ & $\begin{array}{c}\text { Os projetos são anuais, } \\
\text { mas as relações entre os } \\
\text { coordenadores } \\
\text { ultrapassam este período } \\
\text { temporal. O projeto } \\
\text { encontra-se na terceira } \\
\text { edição, e o grupo gestor } \\
\text { praticamente permanece o } \\
\text { mesmo. }\end{array}$ \\
\hline
\end{tabular}

Fonte: Elaborado pelas autoras (2014).

De forma didática, se analisa abaixo os quatro pontos em questão: 1) objetivo; 2) participantes; 3) o que possuem em comum; e 4) tempo de duração.

1) objetivo: Quando se observa o objetivo do projeto, conforme apresentado no quadro13, a prática da coordenação se assemelha com a caracterização de equipe de projetos, anteriormente apresentada por Wenger e Snyder (2001), pois se trata da reunião de um grupo de pessoas capacitadas a fim de realizar determinada tarefa - no caso, auxiliar os alunos no processo de ensino e aprendizagem com relação às Tecnologias da Informação e Comunicação.

2) participantes: No que tange ao aspecto seleção, a coordenação escolhe os seus participantes por meio da autosseleção, o que lhe confere uma das características das Comunidades de Prática. 
3) o que possuem em comum: Referente ao que possuem em comum entre os coordenadores do projeto, existe semelhança com três tipos de grupos apresentados por Wenger e Snyder (2001). Os coordenadores são mestres e doutores com atividades de ensino, pesquisa e extensão voltadas ao ensino a distância, e, assim, apresentam identificação com o conhecimento especializado característica eminente das CoPs. Para além desse aspecto, também possuem metas em comum com relação ao curso (diminuição de evasão, aumento no número de concluintes com êxito, prestação de uma tutoria de qualidade, entre outras) o que é característica do grupo de trabalho formal e da equipe de projeto.

4) tempo de duração: O tempo de duração do projeto é anual, e, desse modo, a coordenação permanece em atuação até o término da edição do projeto e aguarda a autorização por parte do Ministério da Educação para a nova edição, reorganização do projeto. Nesta perspectiva, segundo a classificação de Wenger e Snyder (2001), a equipe gestora se enquadra no grupo de trabalho formal e equipe de projeto. No entanto, como já informado no quadro 13, o projeto se encontra na terceira edição e permanecesse praticamente com o mesmo grupo gestor, o que confere ao grupo mais tempo de convivência. Também é interessante mencionar que os laços se estendem para outros projetos paralelos que os integrantes possuem em comum, e mesmo relações de amizade que ultrapassam o âmbito profissional. Por estas características que ultrapassam o período do projeto, identifica-se que o grupo permanece unido por interesse próprio, por vislumbrarem algo que não está limitado ao projeto Aluno Integrado, o que lhes confere característica de CoP.

Quadro 5 - Caracterização do grupo gestor segundo classificação proposta por WENGER e SNYDER (2001)

\begin{tabular}{|c|c|c|c|c|}
\hline Grupo & Quanto ao objetivo & $\begin{array}{c}\text { Quanto aos } \\
\text { participantes }\end{array}$ & $\begin{array}{c}\text { Quanto ao que tem em } \\
\text { comum }\end{array}$ & $\begin{array}{c}\text { Quanto ao tempo de } \\
\text { duração }\end{array}$ \\
\hline $\begin{array}{c}\text { Grupo gestor do } \\
\text { projeto Aluno } \\
\text { Integrado }\end{array}$ & Equipe de Projetos & $\begin{array}{c}\text { Comunidade de } \\
\text { Prática }\end{array}$ & $\begin{array}{c}\text { Comunidade de Prática } \\
\text { Equipe de Projeto } \\
\text { Grupo de Trabalho } \\
\text { Formal }\end{array}$ & $\begin{array}{c}\text { Comunidade de Prática } \\
\text { Equipe de Projeto } \\
\text { Grupo de Trabalho } \\
\text { Formal }\end{array}$ \\
\hline
\end{tabular}

Fonte: Elaborado pelas autoras (2014). 
Pelo exposto até o momento, percebe-se que o grupo gestor apresenta características de mais de uma forma de associação grupal, mas que prepondera as das CoPs. Frisa-se que o aludido grupo não se declara como uma Comunidade, mas que, por suas características aproximadas dela, vivencia as situações próprias daquela.

Ao retomar algumas conceituações básicas sobre as CoPs, verificamos que o grupo de gestores aproxima-se ainda mais das Comunidades, tais como: "As Comunidades de Prática consistem em grupos informais de pessoas que compartilham conhecimentos e se entusiasmam pela prática organizativa (SCHMITT, 2012)"; "Nas CoPs as pessoas disseminam conhecimento especializado e sentem paixão pelo tema do domínio da Comunidade (WENGER 1998a); "Em tais ambientes, cria-se um espaço social em que os participantes podem descobrir e promover parcerias de aprendizagem relacionadas a um domínio comum (WENGER; TRAYNER; LAAT, 2011)".

Passa-se a formulação de um ranking em que se tem como objetivo facilitar a visualização dos FCS que mais se mostraram relevantes ao grupo. A intenção, portanto, é apontar os fatores que se evidenciaram críticos para o grupo de gestores, prestando-se a condensar, por ordem de importância, os resultados já apresentados. 


\section{Quadro 15 - Ranking dos FCS à manutenção das CoPs para o grupo de gestores do projeto Aluno Integrado}

\begin{tabular}{|c|c|c|}
\hline Ranking & $\begin{array}{l}\text { Somatório da } \\
\text { escala Likert }\end{array}$ & Fatores Críticos de Sucesso à manutenção das CoPs \\
\hline $1^{\circ}$ & 19 & $\begin{array}{l}27 \text { - As ferramentas de tecnologia da informação e comunicação devem facilitar a dinâmica das } \\
\text { atividades das CoPs, e não se constituírem em entraves à participação dos membros. }\end{array}$ \\
\hline $2^{\circ}$ & 17 & $\begin{array}{l}28 \text { - A tecnologia utilizada precisa ser compreendida/dominada para a participação plena dos } \\
\text { membros nas atividades da CoP. }\end{array}$ \\
\hline $3^{\circ}$ & 15 & $\begin{array}{l}24 \text { - A expectativa de benefícios pessoais influencia os membros a participarem de Comunidades. } \\
\text { Exemplos: ascensão profissional, criação de redes de contatos, maior celeridade e racionalização } \\
\text { nas rotinas, compartilhamento de documentos úteis aos seus trabalhos. }\end{array}$ \\
\hline $3^{\circ}$ & 15 & 14 - O suporte da Organização é importante para a manutenção da Comunidade. \\
\hline $4^{\circ}$ & 14 & $\begin{array}{l}17 \text { - Estabelecer de forma clara e objetiva o domínio da CoP, para ciência dos membros e da } \\
\text { organização quanto ao seu conteúdo. }\end{array}$ \\
\hline $4^{\circ}$ & 14 & $\begin{array}{l}9 \text { - O papel do líder, nas Comunidades de Prática, assume características baseadas em diretrizes } \\
\text { como influência, respeito, estímulo intelectual e orientação. }\end{array}$ \\
\hline $4^{\circ}$ & 14 & $\begin{array}{l}1 \text { - A demonstração pública, por parte dos gestores, da importância das atividades das } \\
\text { Comunidades para a organização eleva a autoestima dos membros, o que favorece as suas }\end{array}$ \\
\hline $5^{\circ}$ & 13 & $\begin{array}{l}22 \text { - Se faz necessário o estabelecimento de mecanismos que assegurem aos membros a confiança } \\
\text { sobre a qualidade do conteúdo do conhecimento compartilhado na CoP. }\end{array}$ \\
\hline $5^{\circ}$ & 13 & $\begin{array}{l}21 \text { - A propriedade intelectual deve ser assegurada nas CoPs. Os membros não devem temer pelo } \\
\text { uso impróprio do conhecimento compartilhado por eles. }\end{array}$ \\
\hline $5^{\circ}$ & 13 & $\begin{array}{l}11 \text { - O princípio da autodeterminação deve ser preservado, uma vez que ele possibilita a } \\
\text { sustentabilidade das Comunidades. }\end{array}$ \\
\hline $5^{\circ}$ & 13 & $\begin{array}{l}5 \text { - As informações sobre a Comunidade devem ser divulgadas dentro da organização como meio } \\
\text { de não segregar possíveis interessados, e mesmo de evitar animosidade entre os não membros e os } \\
\text { membros (sentimentos como inveja, desconfiança). }\end{array}$ \\
\hline $6^{\circ}$ & 12 & $\begin{array}{l}26 \text { - Posições hierárquicas, status e poderes dos membros na organização formal podem ser } \\
\text { reproduzidos nas CoPs, e tal situação pode desagregá-la. }\end{array}$ \\
\hline $6^{\circ}$ & 12 & $\begin{array}{l}8 \text { - Os membros necessitam de liberdade para expressar suas opiniões e dúvidas. Mecanismos de } \\
\text { controle sob a CoP baseados em autoridade impedem as contribuições espontâneas. }\end{array}$ \\
\hline $7^{\circ}$ & 11 & $\begin{array}{l}19 \text { - A proximidade cultural entre os membros facilita o compartilhamento do conhecimento entre } \\
\text { os membros das CoPs. }\end{array}$ \\
\hline $7^{\circ}$ & 11 & $\begin{array}{l}13 \text { - Encontros face a face devem ser fomentados nas CoPs. Tais interações são fundamentais para } \\
\text { a construção do sentimento de confiança entre os membros. }\end{array}$ \\
\hline $7^{\circ}$ & 11 & $\begin{array}{l}4 \text { - Comunidades com foco local agem em questões específicas dos membros e, dessa forma, } \\
\text { aumentam os benefícios diretos a eles. }\end{array}$ \\
\hline $7^{\circ}$ & 11 & $\begin{array}{l}2 \text { - As organizações podem propor CoPs aos seus colaboradores, no entanto não devem impor } \\
\text { critérios e processos estruturados. A imposição de normas retira da CoP a sua autodeterminação. }\end{array}$ \\
\hline $8^{\circ}$ & 10 & $\begin{array}{l}20 \text { - A confiança está associada à percepção da Comunidade em aceitar os conhecimentos } \\
\text { disponibilizados em uma base do conhecimento. }\end{array}$ \\
\hline $8^{\circ}$ & 10 & $\begin{array}{l}15 \text { - Realização de avaliações formais dos objetivos, custos e resultados das CoPs é importante } \\
\text { para sua manutenção. }\end{array}$ \\
\hline $8^{\circ}$ & 10 & 12 - As CoPs necessitam da presença de um líder atuante para o seu sucesso. \\
\hline $8^{\circ}$ & 10 & $\begin{array}{l}10 \text { - As CoPs necessitam de um "fator" agregador a fim de estimular a participação dos membros, } \\
\text { seja um membro respeitado pelos demais para atuar como coordenador, seja um grupo gestor. }\end{array}$ \\
\hline
\end{tabular}




\begin{tabular}{|c|c|l|}
\hline Ranking & $\begin{array}{c}\text { Somatório da } \\
\text { escala Likert }\end{array}$ & Fatores Críticos de Sucesso à manutenção das CoPs \\
\hline $9^{\circ}$ & 8 & $\begin{array}{l}23 \text { - Para que ocorra o compartilhamento do conhecimento em uma CoP, os membros precisam de } \\
\text { segurança que seus "poderes" e posições hierárquicas na organização formal não serão perdidos. }\end{array}$ \\
\hline $9^{\circ}$ & 8 & $\begin{array}{l}16 \text { - Os resultados das Comunidades levam tempo para se evidenciarem, assim é necessário } \\
\text { aguardar por seus benefícios. }\end{array}$ \\
\hline $9^{\circ}$ & 8 & 6 - Excesso de trabalho na organização influencia os membros a declinarem das Comunidades. \\
\hline $10^{\circ}$ & 5 & 7 - As CoPs devem ser criadas em torno de temas centrais ao sucesso do negócio da organização. \\
\hline $10^{\circ}$ & 5 & $\begin{array}{l}3 \text { - Somado à falta de tempo, o conflito de prioridades entre o papel de colaborador da organização } \\
\text { e o de membro da CoP pode reduzir a motivação para a participação em CoPs. }\end{array}$ \\
\hline $11^{\circ}$ & 3 & $\begin{array}{l}25 \text { - A percepção de que há desigualdade entre o nível de conhecimento dos membros pode criar } \\
\text { tensões, ressentimentos e desestimular a participação na Comunidade. }\end{array}$ \\
\hline $12^{\circ}$ & 1 & $\begin{array}{l}18 \text { - A heterogeneidade dos membros dificulta o compartilhamento do conhecimento, em virtude } \\
\text { das possíveis diferenças nos níveis de conhecimento quanto ao domínio da CoP. }\end{array}$ \\
\hline
\end{tabular}

Fonte: Elaborado pelas autoras (2014).

O quadro apresentado acima ilustra, por ordem de gradação, os fatores que mais representam as situações críticas à manutenção das Comunidades para o grupo estudado. Percebe-se que alguns possuem um alto grau de importância, outros são medianos, e por fim, fatores pouco relevantes.

Salienta-se, por fim, que esse é um recorte feito para o grupo em análise. Não necessariamente o quadro se replicará em outra Comunidade, visto que, para cada ambiente comunitário, haverá suas peculiaridades que, por sua vez, influenciarão nas avaliações aos fatores sugeridos. No entanto, sob o ponto de vista acadêmico, a enumeração acima efetuada ganha relevância, pois apresenta um início de análise que seguramente auxiliará em estudos futuros, e mesmo, aliado a outros, poderá indicar um norte a fim de se identificar um padrão sobre o tema (fatores críticos mais relevantes).

\section{CONSIDERAÇÕES FINAIS}

Atualmente, no processo de criação e desenvolvimento do capital humano, as Comunidades de Prática firmam, de vez, sua relevância como preciosa ferramenta da Gestão do Conhecimento, que pode se prestar ao auxílio dos mais diversos segmentos sociais. São equipes de professores, médicos e membros de empresas e instituições, entre outros, que encontram em tais grupos o instrumento materializador e potencializador das cinco fases do processo de GC, quais sejam, identificação, retenção, aplicação, criação e disseminação. 
Diante desse quadro, inegável que o estudo dos fatores críticos de sucesso à manutenção das CoPs passou a ser, indistintamente, questão crucial a todas as organizações: desde aquelas que pretendem ser reconhecidas como criadoras de capital humano até as que almejam sua sobrevivência.

Nesse entendimento, este estudo apresentou como objetivo geral de pesquisa resgatar os fatores críticos de sucesso à manutenção das Comunidades de Prática apresentados por Schmitt (2012) e verificar a aderência daqueles a um grupo de gestores que possui características preponderantemente a de uma Comunidade de Prática. Com o escopo de se alcançar a resposta a essa questão, dois objetivos específicos foram traçados, que são:

Como resultado à pergunta de pesquisa, foi possível estabelecer um ranking com os 28 fatores críticos de sucesso à manutenção das Comunidades e o grau de importância que estes se apresentaram ao grupo de gestores do projeto Aluno Integrado. Ademais, foi possível demonstrar que os fatores apresentados pela literatura possuem aderência à realidade do grupo, alguns em maior e outros em menor escala.

Ao final deste artigo, verifica-se que a experiência advinda do estudo de caso somente reforçou a ideia, já defendida na literatura, acerca da relevância de se determinar pontos que possam impulsionar ou obstar a manutenção das Comunidades. Isso porque, uma vez identificados tais fatores, se pode adotar estratégias específicas a fim de aprimorar a gestão e o desempenho do ambiente comunitário, assegurando a sobrevivência dessa ferramenta extremamente valiosa à sustentabilidade de qualquer organização. 


\section{REFERÊNCIAS}

ALUNO INTEGRADO. Histórico. UFSC. Disponível em:

<http://2010.alunointegrado.ufsc.br/node/2>. Acesso em 25 abr. 2014.

ALUNO INTEGRADO. Aluno Integrado 2014. UFSC. Disponível em: <http://alunointegrado.ufsc.br/>. Acesso em 16 maio 2014.

ARDICHVILI, A.; PAGE, V.; WENTLING, T. Motivation and barriers to participation in virtual knowledge-sharing communities of practice. Journal of Knowledge Management, v.7, n. 1, p. 64-77, 2003.

ASIAN PRODUCTIVITY ORGANIZATION (APO). Knowledge Management Tools and Techniques Manual. Tokyo: Asian Productivity Organization, 2010.

DALKIR, K. Knowledge management in theory and practice. Mcgill University, Burlington, Elsevier, 2005.

FONTAINE, Michael A.; MILLEN, David R. Understanding the benefits and impact of communities of practice. HILDRETH, Paul; KIMBLE, Chris (Org.) Knowledge networks: innovation through communities of practice. London: Idea Group Publishing, p. 1-13, 2004.

GIL, Antônio Carlos. Como elaborar projetos de pesquisa. 5. ed. São Paulo: Atlas, 2010.

LAVE, J.; WENGER, E. Situated Learning: Legitimate Peripheral Participation. Cambridge: Cambridge University Press, 1991.

LI, Z.; ZHU, T.; LAI, Wendi. A study on the knowledge diffusion of communities of practice based on the weighted small-world network. Journal of Computers, v.5, n.7, p. 1046-1053, 2010.

MCDERMOTT, R. Critical success factors in building communities of practice. Knowledge Management Review, v.3, n.2, p. 5, 2000. Disponível em:<http://www.mcdermottconsulting.com/images/Articles/SME\%20-\%2010\%20Critical\% 20Success\%20Factors.pdf> Acesso em: 26 jul. 2015.

MCNABB, David E. Knowledge management in the public sector: a blueprint for innovation in government. Armonk, Nova York: ME Sharpe, Inc., 2007.

SANTOS, Fladimir F. dos. Modelo de gestão para promover a criação e o compartilhamento de conhecimento em Comunidade virtual de prática. 2010, 242 p. Tese. Doutorado em Engenharia e Gestão do Conhecimento, Universidade Federal de Santa Catarina, Florianópolis, 2010.

SANTOS, N.. Gestão do Conhecimento Organizacional. Apostila criada para o Programa de Pós-Graduação em Engenharia e Gestão do Conhecimento. Florianópolis, 2005. 
SCARSO, Enrico; BOLISANI, Ettore. Communities of practice as structures for managing knowledge in networked corporations. Journal of Manufacturing Technology Management, v.19, n.3, p. 374-390, 2008.

SCHMITT, Sabrina Rebelo. Fatores críticos de sucesso à manutenção de Comunidades de Prática e suas dimensões de análise. 2012, 170 p. Dissertação. Mestrado em Engenharia e Gestão do Conhecimento, Universidade Federal de Santa Catarina, Florianópolis, 2012.

VERGARA, Sylvia Constant. Projetos e relatórios de pesquisa em administração. 9 ed. São Paulo: Atlas, 2007.

VON WARTBURG, I.; ROST, K.; TEICHERT, T. The creation of social and intellectual capital in virtual communities of practice: shaping social structure in virtual communities of practice.

International Journal of Learning and Change, v.1, n. 3, p. 299-316, 2006.

WENGER, E. Communities of Practice: Learning, Meaning and Identity. Cambridge:

Cambridge University Press, New York, 1998a.

Communities of Practice: Learning as a social system. (1998b). Disponível em:

<http://iatefl.britishcouncil.org/2012/sites/iatefl/files/session/documents/learning_as_a_social_sy stem_cofp_wenger.pdf $>$. Acesso em: 20 jun. 2012.

. Communities of Practice and social learning systems. Journal Organization, v.7, n.2, p. 225-246, 2000.

Sistemas de Aprendizagem Social (2012). Disponível em:

<http://www.sbgc.org.br/sbgc/kmbrasil/noticia/2012/Comunidades-pratica-e-sistemasaprendizagem-social-por-etienne-wenger> Acesso em: 08 ago. 2012.

WENGER, E.; MCDERMOTT, R.; SNYDER, W. M. Cultivating communities of practice: a guide to managing knowledge. Boston: Harvard Business School Press, 2002a.

Seven principles for cultivating communities of practice. (2002b). Disponível em: <http://hbswk.hbs.edu/archive/2855.html> Acesso em: 23 jun. 2012.

WENGER, E.; SNYDER, W. M. Communities of Practice: The Organizational Frontier. Harvard Business Review, jan./fev., p. 139- 145, 2000.

Comunidades de prática: a fronteira organizacional. In: Vários autores. Aprendizagem Organizacional. Tradução de Cássia Maria Nasser. Rio de Janeiro: Campus, 2001. p. 9-26.

WENGER, E.; TRAYNER, B.; LAAT, M.. Promoting and assessing value creation in communities and networks: a conceptual framework. (2011). Disponível em: <http://www.open.ou.nl/rslmlt/Wenger_Trayner_DeLaat_Value_creation.pdf > Acesso em: 28 maio 2012.

ZBORALSKI, Katja. Antecedents of knowledge sharing in communities of practice. Journal of Knowledge Management, v.13, n.3, p. 90-101, 2009. 